S. Martín Martín*, R. Calvo González, E. García Lagarto y

E. Fernández Del Busto

Servicio de Urología, Hospital Clínico Universitario de Valladolid, Valladolid, España
*Autor para correspondencia.

Correo electrónico: Risimartin7@hotmail.com

(S. Martín Martín).

\title{
Carcinoma escamocelular condilomatoso asociado al virus del papiloma humano multimetastásico
}

\section{Condylomatous cell carcinoma of the penis associated human papillomavirus with multimetastatic}

\section{Sr. Director:}

El cáncer de pene presenta actualmente una incidencia baja en los países desarrollados (alrededor de 0,5-1 por cada 100.000 habitantes) frente a una incidencia moderada en los países en vías de desarrollo o subdesarrollados (20-25 por cada 100.000 habitantes). Existen distintos tipos histológicos de localización primaria e incluso se han descrito casos de histología atípica con localización peneana, así como metástasis peneanas de otros carcinomas.

Presentamos el caso de un paciente de 67 años de edad con antecedentes personales de diabetes mellitus insulino-dependiente, hipertensión arterial y miocardiopatía dilatada, que consulta por presentar una lesión excrecente, ulcerada en el pene, junto con dificultad para la micción de 5 meses de evolución. A la exploración se aprecia una lesión excrecente, friable y ulcerada, localizada en el glande, de gran tamaño, sin identificar estructuras anatómicas normales (fig. 1). Se realiza un estudio analítico en el que no se aprecia ninguna alteración significativa, una TAC abdominopélvica en la que

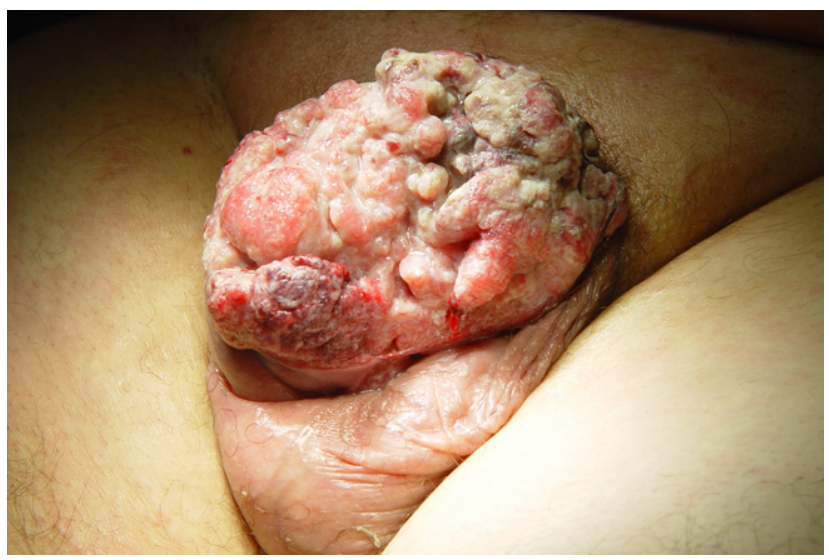

Figura 1 - Lesión excrecente y ulcerada localizada en el pene. se aprecian múltiples adenopatías retroperitoneales, un nódulo de $1 \mathrm{~cm}$ en el segmento III hepático, múltiples nódulos hipoatenuantes en el bazo (fig. 2), nódulo adrenal derecho, soluciones de continuidad en pala ilíaca derecha, todas ellas compatibles con metástasis. En la radiografía de tórax se aprecia un nódulo en la base pulmonar derecha compatible con metástasis. Se decide realizar penectomía total y uretrostomía perineal. A las $72 \mathrm{~h}$ de la intervención el paciente presenta disartria y síndrome vertiginoso, por lo que se solicita una TAC cerebral en la que se aprecian múltiples nódulos compatibles con metástasis. El informe histológico de la muestra fue informado como carcinoma escamocelular variante condilomatoso con positividad antigénica para el virus del papiloma humano tipo 16 (T3N2M1). Se decidió instaurar tratamiento paliativo, el paciente falleció a los 20 días de la intervención.

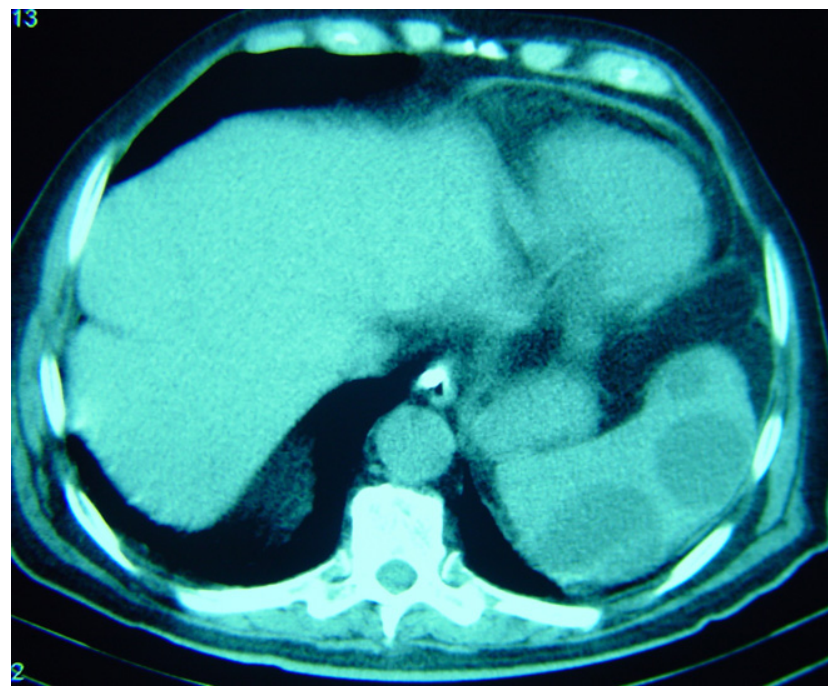

Figura 2 - TAC: nódulos esplénicos compatibles con metástasis. 
El carcinoma escamoso o epidermoide es el más frecuente de los tumores malignos que asientan en el pene, diferenciándose tres grados histológicos según el nivel de diferenciación celular. Se consideran factores de riesgo relacionados con esta patología una pobre higiene, presencia de fimosis e infección por el virus del papiloma humano ${ }^{1,2}$. Se consideran factores preventivos las medidas higiénicas, la circuncisión, el uso de condón, el abandono del tabaco y el tratamiento de lesiones inflamatorias crónicas ${ }^{3}$. El diagnóstico de esta patología es fundamentalmente clínico, siendo precisa la realización de pruebas de imagen (ecografía o resonancia nuclear magnética) para valorar el grado de invasión local ${ }^{4}$. En caso de sospecha clínica de invasión tumoral a distancia está indicada la realización de TAC abdominopélvica y radiografía simple de tórax para valorar enfermedad metastásica ${ }^{1}$.

Clásicamente, el tratamiento de esta patología consiste en realizar penectomía parcial o total en función del grado de invasión tumoral. En los últimos años ha quedado demostrado que para las lesiones que no invaden cuerpos cavernosos o esponjosos y con buen grado de diferenciación celular está indicada la terapia conservadora con el uso de crioterapia, láser, imiquimod al 5\%, fluorouracilo, radioterapia, braquiterapia o terapia fotodinámica ${ }^{1,5}$, mientras que para los tumores localmente invasivos se indica una cirugía más radical (penectomía total o parcial). En aquellos pacientes con diseminación a distancia el tratamiento es diferente en función de la localización metastásica. Si presentan adenopatías inguinales palpables el tratamiento de elección en estos casos es la linfadenectomía ${ }^{6}$, mientras que si no existen adenopatías palpables hay controversia sobre el tratamiento complementario para realizar y dependerá del grado de invasión local del tumor y del grado de diferenciación celular. En los casos donde existen metástasis a distancia se indica tratamiento paliativo o quimioterapia con cisplatino, metotrexato y bleomicina que ha demostrado ser eficaz y ha demostrado aumentar la supervivencia en casos de afectación linfática ${ }^{7}$, pero no así en aquellos pacientes con diseminación tumoral orgánica.

El pronóstico de estos pacientes depende de una multitud de factores. Novara et al en una revisión sistemática ponen de manifiesto que la presencia de grado histológico alto, infiltración de cuerpos cavernosos, infiltración de cuerpo esponjoso, infiltración uretral y presencia de adenopatías se asocia a una disminución de la supervivencia y a un peor pronóstico $^{8}$. Por su parte, Madeira Campos et al demuestran que la presencia de una baja inmunorreactividad a E-cadherina se relaciona con un alto riesgo de metástasis linfáticas y un pobre pronóstico, no así la inmunorreactividad para MMP-2 y MMP-9 para la cual no encuentran relación con la afectación linfática ${ }^{9}$. Zhu et al demuestran que la inmunorreactividad del p53 es útil para establecer la probabilidad de enfermedad linfática, así como ser un buen marcador en el pronóstico y seguimiento de estos pacientes tras el tratamiento ${ }^{10}$.

Por tanto, consideramos actualmente el cáncer de pene como una patología tumoral agresiva, con un alto índice de metastatización a distancia, sobre todo por vía linfática, y cuyo tratamiento más habitual es la penectomía. En casos como el que presentamos, con múltiples metástasis a distancia sólo cabe la posibilidad por el momento de realizar un tratamiento paliativo, ya que en estos casos el tratamiento quimioterapéutico no obtiene beneficio por los altos índices de citotoxicidad causantes.

B I B L I O G R A F Í A

1. Solsona E, Algaba F, Horenblas S, Pizzocaro G, Windahl T. EAU guidelines of penile cancer. Eur Urol. 2004;46:1-8.

2. Backes DM, Kurman RJ, Pimenta JM, Smith JS. Systematic review of human papillomavirus prevalence in invasive penile cancer. Cancer causes control. 2008.

3. Bleeker MC, Heideman DA, Snijders PJ, Horenblas S, Dillner J, Meijer CJ, et al. Penile cancer: Epidemiology, pathogenesis and prevention. World J Urol. 2008.

4. Andipa E, Liberopoulos K, Asvestis C. Magnetic resonance imaging and ultrasound evaluation of penile and testicular masses. World J Urol. 2004;22:382-91.

5. Singh I, Khaitan A. Current trends in the management of carcinoma penis-a review. Int Urol Nephrol. 2003;35:215-25.

6. Culkin DJ, Beer TM. Advanced penile carcinoma. J Urol. 2003;170:359-65.

7. Hakenberg OW, Nippgen JB, Froehner M, Zastrow S, Wirth MP. Cisplastin, methotrexate and bleomycin for treating advanced penile carcinoma. BJU int. 2006;98:1225-7.

8. Novara G, Galfano A, De Marco V, Artibani W, Ficarra V. Prognostic factors in squamous cell carcinoma of the penis. Nat Clin Pract Urol. 2007;4:140-6.

9. Campos RS, Lopes A, Guimarães GC, Carvalho AL, Soares FA. E-cadherin, MMP-2 and MMP-9 in penile cancer: Analysis of 125 patients. Urology. 2006;67:797-802.

10. Miranda Aranzubía O, García Rodríguez J, González Álvarez RC, Álvarez Mujica M, Rodríguez Robles L, Regadera Sejas J. Condiloma acuminado gigante (tumor de BuschkeLöwenstein). Actas Urol Esp. 2008;32:951.

M.A. Arrabal-Polo ${ }^{a, *}$, S. Arias-Santiago ${ }^{a, b}$, A. Jiménez-Pacheco ${ }^{a}$ y A. Zuluaga-Gómez ${ }^{a}$

aServicio de Urología, Hospital Universitario San Cecilio, Granada, España

bServicio de Dermatología, Hospital Universitario San Cecilio, Granada, España

*Autor para correspondencia.

Correo electrónico: arrabalp@ono.com (M.A. Arrabal-Polo). 